\title{
Voodoo versus fishing committees: the role of traditional and contemporary institutions in fisheries management
}

\author{
Briones Alonso, Elena ${ }^{\mathrm{a}} \quad$ Houssa, Romain $^{\mathrm{b}} \quad$ Verpoorten, Marijke $^{\mathrm{a}, \mathrm{c}}$
}

\begin{abstract}
${ }^{a}$ Centre for Institutions and Economic Performance (LICOS), University of Leuven (KU Leuven). Corresponding author: elena.brionesalonso@kuleuven.be.

${ }^{\mathrm{b}}$ Centre of Research in the Economics of Development (CRED) and CeReFiM, University of Namur (UNamur)

${ }^{\mathrm{c}}$ Institute for Development Policy and Management (IOB), University of Antwerp (UA)
\end{abstract}

\begin{abstract}
We study the co-existence of two community-based institutions for fisheries management in Benin: a traditional institution embedded in the Voodoo religion and a recent secular institution in the form of fishing committees. Using household survey data on fishing activities, we find that rules of both institutions have a statistically significant but small impact on the use of unsustainable fishing gear. We further find that Voodoo fishers who break the traditional Voodoo-based rule follow the fishing committee rule to the same extent as other fishers. This finding is consistent with a possible transition from the traditional Voodoo-based institution to the secular fishing committee institution. More research is needed to fully assess the effectiveness of, and interactions between, the two institutions.
\end{abstract}

Key words: Community-based natural resource management; institutions; religion; Voodoo; fisheries; Benin 


\section{Introduction}

Around the globe, marine and inland fishery stocks are being overexploited (Allan et al., 2005; FAO, 2012). The importance of small-scale fisheries for food security and poverty alleviation stresses the need for sustainable fisheries management (FAO, 2014). Community-based natural resource management has been advocated as an effective and sustainable resource management strategy under certain conditions (Agrawal, 2001; Baland and Platteau, 1996; Berkes, 1989; Cox et al., 2010; Ostrom, 1990), in particular for small-scale fisheries (Berkes, 2001; Pinkerton, 2011).

Community-based natural resource management is often integrated in traditional culture or religion, relying on institutions such as sacred sites and taboos (Berkes, 2008; Berkes et al., 2000; Bhagwat and Rutte, 2006; Colding and Folke, 2001; Dudley et al., 2009; Jones et al., 2008). Although traditional resource management is often undermined by socio-economic modernization and the introduction of new institutions and religions, case studies find that traditional religions continue to regulate resource exploitation and conservation today (Deb and Malhotra, 2001; Eneji et al., 2012; Kajembe et al., 2003; Kokou et al., 2008; NtiamoaBaidu, 2008; Ormsby and Bhagwat, 2010; Sharma et al., 1999; Veitayaki et al., 2011).

In this paper we examine community-based fisheries management at Lake Nokoué in Benin. The lake fisheries provide a livelihood to artisanal fishing communities, but are severely affected by overfishing and resource degradation (FAO, 2008; Gnohossou, 2006). Fishing was historically regulated by an institution embedded in Voodoo, the traditional animistic religion of Benin (Bourgoignie, 1972; Clédjo, 2006; Dangbégnon, 2000; Pliya, 1980). After colonization, socio-economic changes undermined the influence of the Voodoo religion and Voodoo-based institutions. The erosion of traditional fisheries management in combination with failing government institutions, strong population pressure and the rising value of fishery 
products resulted in increasingly severe overfishing (Dangbégnon, 2000). In the 1990s the fishing communities attempted to curb this negative trend by creating committees to regulate fishing activities (Atti-Mama, 1998).

These fishing committees issued rules that differ and sometimes conflict with traditional Voodoo-based rules. For instance, both the committees and the traditional institution formulate a rule concerning the konou - a highly productive fishing technique that makes use of fine mesh nets. The traditional rule bans the use of the fine meshed konou at all times (Clédjo, 2006; Pliya, 1980), while the fishing committees impose a periodical prohibition: open weeks - in which the use of the konou is allowed - alternate with closed weeks - in which the konou is banned.

In this dual institutional setting we examine three empirical questions. First, does the traditional Voodoo-based rule still keep Voodoo fishers from using the fine meshed konou? Second, does the fishing committee rule keep fishers from using the konou in closed weeks? Third, do Voodoo fishers who break the traditional Voodoo rule comply in any way to the fishing committee rule?

To answer these questions, we perform an empirical analysis using two different datasets. The first is taken from a 2006 fishery census implemented by the Beninese government, and contains information for 5,852 fishermen across 34 villages near lake Nokoué. The second is a 2009 household survey implemented by the authors, and contains weekly information on fishing activities across 14 weeks for 103 fishermen living near lake Nokoué. While the large census allows us to better control for village level heterogeneity, the household survey has the advantage of a weekly time dimension. To contextualize our analysis we went back to the field in 2013 and surveyed 137 fishers at lake Nokoué, collecting additional information about fishermen's perceptions of fishery institutions.

To examine compliance to the traditional Voodoo-based rule we explore the conditional correlation between Voodoo adherence and the use of the konou, both in the large census data 
and in the household survey data. To examine compliance to the fishing committee rule we study the relation between the use of the konou and the closing of the lake across weeks. As this approach requires a time dimension, we use the household survey data. We also use the survey data to study how Voodoo fishers who break the traditional rule behave towards the fishing committee rule. More specifically, we explore the relation between the use of the konou and the interaction term between Voodoo adherence and the closing of the lake.

To our knowledge this is the first study that quantitatively examines the compliance of resource users to rules formulated by a traditional institution as well as a competing secular institution. In addition, we did not find studies discussing the interaction between traditional and recent management institutions, i.e. how resource users who break with traditional rules behave towards recent alternative rules. Benin provides an ideal testing ground to answer these questions because of its particular setting of dual community-based fishery institutions and because of its remarkable religious tolerance and pluralism, which manifests itself amongst others in considerable variation in religious adherence within villages (Barbier and DorierApprill, 2002). We can therefore compare the behaviour of fishers who explicitly identify themselves with Voodoo to fishers who follow other religions while controlling for villagelevel characteristics.

The next section discusses fishery management institutions and the social-ecological system of lake fisheries in southern Benin. Section 3 presents our data and Section 4 explains the methodology used to analyse the data. Section 5 presents our results, and in Section 6 we investigate a number of competing explanations for our findings. Section 7 concludes. 


\section{The lake fisheries of southern Benin}

\subsection{The social-ecological system}

We study fishing communities living in the commune So-Ava near lake Nokoue in the south of Benin (see Figure 1). Lake Nokoué is the largest water body in Benin and part of the most productive water basin, accounting for 65 to 70 percent of inland fisheries production (Gnohossou, 2006). In the course of history different ethnic groups settled around the lake and specialized in fishing activities (Bourgoignie, 1972; Pliya, 1989, 1980). Today the communities have a long-established tradition of artisanal fishing that dates back several generation, and industrial fishing remains absent (Atti-Mama, 1998).

In recent years, the coastal lakes in Benin suffered from severe environmental degradation and overfishing (FAO, 2008; Gnohossou, 2006). ${ }^{1}$ As the fishing communities have few income activities outside the fishery sector, they are particularly vulnerable to resource degradation (Stoop et al., 2013). ${ }^{2}$ Instead of diversifying their income, the communities cope with the rising pressure on their livelihoods by developing more productive fishing technologies. One of the most important innovations in fishing techniques was the introduction of the konou in the 1980s.

The konou (or medokpokonou) is a fixed fishing installation used in circulating water that consists of a long (100 to $400 \mathrm{~m}$ ) central rectangular net with several pouches (République du Bénin, 2008). This structure and the length of the net make the konou one of the most productive fishing instruments used at lake Nokoué. These features also explain why installing and harvesting the konou requires considerable physical effort.

\footnotetext{
${ }^{1}$ In the 2006 fishery census about $99 \%$ of more than 14,000 fishers at lake Nokoue report that the size of catches and average catches have declined in the last 3 years.

${ }^{2}$ In the 2009 household survey over $85 \%$ of annual household income derives from the fishery sector (see Table A.1 in the online appendix).
} 
The konou is considered an unsustainable fishing technique mainly because of the use of fine mesh fishing nets (20 to $5 \mathrm{~mm}$ ). While these fine mesh nets make the konou very productive, especially for shrimp fishing, they undermine the sustainability of the fishery stock by catching juveniles and even eggs (République du Bénin, 2008).

\subsection{Fisheries management}

\section{The traditional Voodoo-based institution}

Voodoo (Vodun) is an animistic religion found along the coast of West Africa (Ghana, Togo, Benin, Nigeria). From the end of the $16^{\text {th }}$ century until the colonization and subsequent introduction of Christian religions, Voodoo was the dominant religion in South Benin and played a fundamental part in all aspects of society (Bourgoignie, 1972; Tall, 1995b).

In the world view of Voodoo, the natural world is connected to a supreme divine force through Voodoo deities (Bourgoignie, 1972; Tall, 1995a). These deities are immaterial beings, neither human nor divine, that belong to the spirit world. Each spirit is connected to and controls specific natural elements such as trees or water bodies. Voodoo spirits are both respected and feared, as they will help mankind when appeased, but will inflict punishments such as flooding, sickness or even death when offended.

The Voodoo religion gave birth to institutions that regulated the exploitation of natural resources. One example is the sacred forest, found throughout Benin and Togo (Juhé-Beaulaton and Roussel, 2002; Kokou et al., 2008). The southern lakes of Benin provide another example. Voodoo spirits are believed to control the movements of the water and its fauna (Bourgoignie, 1972; Clédjo, 2006; Pliya, 1980), and fishing activities were regulated by a wide array of concrete rules and taboos embedded in Voodoo beliefs (Clédjo, 2006; Pliya, 1980). Fishing was for instance prohibited on days of worship (one day out of four) and in the vicinity of sacred sites (fétiches). The use of fine mesh nets was also prohibited. According to Clédjo (2006) these 
rules served to limit fishing intensity and protect fishery reproduction, for instance by converting spawning grounds into fétiches or shrines.

Voodoo priests were powerful religious and political leaders and played a crucial role in the organization, monitoring and enforcement of the traditional Voodoo-based fishery institution (Dangbégnon, 2000; Pliya, 1980). Sanctions were applied by priests and were severe, ranging from the confiscation of fishing gear to public flagellation. The worst offenses were sanctioned by death.

According to Pliya (1980) the traditional institution managed to keep resource exploitation in check, even in the face of population growth. The system started to fail, however, when (post-)colonial Benin underwent profound changes, such as the disappearance of traditional politico-religious power structures, an increasing market demand for fishery products and the rising popularity of Christian religions (Dangbégnon, 2000; Pliya, 1980). ${ }^{3}$

Even though the religious landscape in post-colonial Benin became dominated by Christianity, the traditional Voodoo religion remains influential today (Tall, 1995a). In 201113 $\%$ of Beninese reported to follow traditional religion (Afrobarometer 2014). Voodoo has also been recorded as an official religion in the constitution and is celebrated each year in a national Voodoo festival.

Similarly, the traditional fishery institution did not disappear. Several rules, taboos and sanctions still exist today (Clédjo, 2006; Dangbégnon, 2000; République du Bénin, 2008). One such rule is the taboo of fishing near fétiches. In our 2013 survey, $85 \%$ of fishers were aware of such fétiches and, among these fishers, $91 \%$ said not to fish near them. Another rule that remains today is the prohibition to use fine mesh nets. Although the death sentence is no longer applied, present-day sanctions can range from the destruction of fishing gear to heavy fines and even the demolition of the perpetrator's house (Clédjo, 2006).

\footnotetext{
${ }^{3}$ See online appendix $\mathrm{C}$ for more details.
} 


\section{The fishing committees}

In 1993 fishers created a new institution to regulate fishing activities in the form of fishing committees (Atti-Mama, 1998). This institution was a local response to overfishing, failing fisheries management and increasingly frequent conflicts. In 1997 the government legalized the fishing committees to increase their effectiveness (République du Bénin, 1997). As such the committees became a co-management institution, organized at the level of the fishing village but legitimized and supported by the central government (Atti-Mama, 1998). The main tasks of the committees - as reported by fishers in 1996 - are the settling of conflicts, implementing and monitoring regulations such as the meshing of nets, protecting the resource and sensitizing fishers (Atti-Mama, 1998). Each village or group of villages has a committee representing all fishers. The committee members are fishers from the village, elected in a village assembly for a (renewable) mandate of three years (République du Bénin, 1997).

The fishing committees created a new rule for the konou that allows its use during four consecutive weeks (open weeks) and bans it for the following two weeks (closed weeks). These periods of open and closed weeks alternate throughout the shrimp fishing season (January August) when larvae migrate from the ocean to the lake, mature and return to the ocean (Hoestlandt, 1939). By periodically banning the use of the konou across the entire lake, the rule intends to reduce the damaging impact of the konou. Fishers are well informed about the rule: in the 2013 survey, only one out of 137 fishers said not to know it.

The fishing committees impose a number of sanctions when the rule is violated, such as the confiscation of fishing gear or catches. However, the effectiveness of the sanctioning mechanism is said to be undermined by corruption (Dangbégnon, 2000). 


\section{Data}

\subsection{Data sources}

For our empirical analysis, we rely on two different datasets. The first is a 2006 fishery census, administered by the Beninese government in southern Benin. The census includes individuallevel information on 27,568 actors in the fishery sector. Our analysis relies on a sample of 5,852 fishers (full-time, part-time and seasonal fishers) living in 34 villages across 10 arrondissements around lake Nokoué. ${ }^{4}$

The second dataset is a household survey administered in April-July 2009 by the authors among 180 households at lake Nokoué. The households were selected by taking a stratified random sample from the 2006 fishery census in six villages, located in two different arrondissements in the commune So-Ava near lake Nokoué (see Figure 1). These households were visited bi-weekly during a period of 14 weeks. ${ }^{5}$ Hence, in contrast to the census data the household survey has a time dimension. In particular, the survey provides detailed weekly information on the fishing activities of 200 fishermen.

In our empirical analysis we focus on those fishermen whose main occupation is fishing and who were visited in all 14 weeks. ${ }^{6}$ This baseline sample counts 103 fishermen. For one aspect of our empirical analysis we look at a subsample of these fishers, namely the konou users. We define a konou user as a fisher who reports to have used the konou at least once during the survey period. This subsample includes 47 fishers living in five villages across two arrondissements. $^{7}$

\footnotetext{
${ }^{4}$ The arrondissement is the administrative unit in-between the village and the commune level.

${ }^{5}$ See online appendix B for more information on survey implementation.

${ }^{6}$ We explain this choice in section A.3.1.of the online appendix.

${ }^{7}$ One village (Sokomey) drops out compared to the baseline sample because there was no konou user among the sample fishers in this village. All but one of the sample fishers in Sokomey are Voodoo adherents.
} 
Finally, during an additional field visit we collected supplementary information on fishermen's perceptions of fishery institutions. This visit took place in April 2013, when we surveyed 137 fishermen across three villages at lake Nokoué. These fishers are a subsample of the fishers interviewed in the 2009 household survey. Table 1 summarizes the key characteristics of each data sample used in the paper.

\subsection{Descriptive statistics}

Summary statistics of individual and household characteristics in the 2009 household survey and 2006 fishery census samples are reported in the online appendix (Table A.1). Below we report descriptive statistics for our key variables: religious adherence and the use of konou.

Table 2 presents the variation in religious affiliation in our two main datasets. The distribution is similar across the two samples, with Voodoo and Catholicism being the main religions. In the census $24 \%$ of fishers are Voodoo adherents, compared to $27 \%$ in the household survey.

Table 3 presents the share of konou users among Voodoo adherents and among all other fishers. In both samples the share of konou users is lower among Voodoo adherents. In the household survey the difference is most pronounced: only $29 \%$ of Voodoo fishers are konou users compared to $52 \%$ of other fishers. ${ }^{8}$

The bars in Figure 2 give the share of fishers that report using the konou in each week in the household survey. The konou is generally used less in closed weeks compared to open weeks, in particular in the first week of closing. The difference, although small, is statistically significant at the $1 \%$ level.

\footnotetext{
${ }^{8}$ The difference in konou use across Voodoo adherents and other fishers is statistically significant at the $1 \%$ level in the census sample and at the $2 \%$ level in the survey sample.
} 


\section{Data analysis}

\subsection{The traditional rule}

To examine compliance to the traditional Voodoo rule, which prohibits the use of the fine meshed konou at all times, we exploit variation in Voodoo adherence across and within villages in both the household survey and the fishery census sample.

For the household survey sample we estimate the following equation:

Konou $_{i t}=\alpha_{0}+\alpha_{1}$ Voodoo $_{i}+\tau_{t}+\lambda_{a}+X_{i}^{\prime} \Omega+\varepsilon_{i t a}$

Konou $_{i t}$ is an indicator variable taking value 1 if individual $i$ reports to have used the konou in week $t$ (and 0 otherwise) $)^{9} ; \operatorname{Voodoo}_{i}$ is an indicator variable that equals 1 if individual $i$ reports his religion to be Voodoo (and 0 otherwise); $\tau_{t}$ is a count variable that indicates the week of the survey period; $\lambda_{a}$ are dummy variables at the arrondissement level that capture time-invariant community characteristics; $X_{i}^{\prime}$ is a vector of control variables; $\varepsilon_{i t a}$ denotes the random error term. To deal with serial correlation of the error terms we cluster error terms at the individual level, thereby allowing error terms to be correlated within individuals (across weeks) while still imposing independence of the error terms between individuals (Wooldridge, 2010).

The time variable $\tau_{t}$ is included to capture unobserved time-varying environmental factors affecting the use of the konou, such as the growth cycle of shrimp. The 2009 household survey was implemented during the shrimp season (January-August). In this period, the quantity and size of shrimp in lake Nokoué gradually increase, which may affect a fisherman's incentive to use the konou. Other environmental factors that typically change as the fishing season progresses are water characteristics such as salinity and transparency.

\footnotetext{
${ }^{9}$ The time dimension is not essential for our hypothesis test in this case, as Voodoo is time-invariant. In section A.3.3. of the online appendix we explain why we use it for our baseline estimations.
} 
The list of control variables $X_{i}^{\prime}$ contains the logarithms of age, years of education and annual income of the fisher, and the size and dependency ratio of his household. We control for age because installing and handling the konou requires considerable physical strength. Years of education are included to control for access to other income sources. Annual income captures wealth, and controls for the fact that the konou is an expensive instrument to purchase and maintain. ${ }^{10}$ Household size and the dependency ratio capture the need of fishers to use highyielding fishing instruments, to earn enough income or to bring home enough food.

The variable of interest in Eq.(1) is Voodoo adherence. A significantly negative estimate for $\alpha_{1}$ would indicate that Voodoo fishermen use the konou less than other fishermen, on average. Assuming that we are adequately controlling for confounding factors, this result would suggest that Voodoo fishermen respect the traditional Voodoo rule more than other fishermen.

An important confounding factor that is however not addressed in Eq.(1) is unobserved village-level heterogeneity. The estimate of $\alpha_{1}$ may be biased if, for instance, villages with a large share of Voodoo adherents are located in areas that are less suitable for the use of the konou. The household survey sample does not allow us to meaningfully control for villagelevel heterogeneity because of the small sample size and proximity of the villages. We therefore make use of the larger 2006 fishery census sample (34 villages) to estimate the following equation:

Konou $_{i}=\alpha_{0}{ }^{\prime}+\alpha_{1}{ }^{\prime}$ Voodoo $_{i}+\varphi_{v}+\Phi_{i}^{\prime} Y+\varepsilon_{i v}$

Konou $_{i}$ is an indicator variable taking value 1 if individual $i$ reports to use the konou for fishing (and 0 otherwise); $\operatorname{Voodoo}_{i}$ is as specified in Eq.(1); $\varphi_{v}$ are village dummy variables; $\Phi_{i}^{\prime}$ is a vector of control variables; $\varepsilon_{i v}$ denotes the random error term, in this case clustered at the

\footnotetext{
${ }^{10}$ Controlling instead for the logarithm of the value of assets yields highly similar results. In any case, in our sample Voodoo fishers are on average richer than other fishers in terms of annual income and asset holdings.
} 
village level to allow for within-village correlation of the error terms across individuals. The set of control variables $\Phi_{i}^{\prime}$ consists of the logarithm of age, a categorical variable indicating the level of education, the number of children in the household ${ }^{11}$ and ethnicity dummy variables. ${ }^{12}$ A significantly negative estimate of $\alpha_{1}{ }^{\prime}$ would indicate that any negative relation between Voodoo adherence and the use of the konou holds when accounting for unobserved villagelevel heterogeneity.

\subsection{The fishing committee rule}

To identify compliance to the fishing committee rule, which prohibits the use of the konou in closed weeks and allows it in open weeks, we exploit the time dimension in the 2009 survey. We study the variation in the use of the konou across open and closed weeks in the subsample of konou users (i.e. fishers that used the konou at least once) by estimating the following equation:

Konou $_{i t}=\beta_{0}+\beta_{1}$ Closed $_{t}+\tau_{t}+\lambda_{a}+X_{i}^{\prime} \Omega+\varepsilon_{i t a}$

Closed $_{t}$ is an indicator variable taking value 1 if the lake is closed in week $t$ (and 0 otherwise); all other variables are as specified in Eq.(1). A significantly negative estimate for $\beta_{1}$ would indicate that the use of the konou is on average lower in closed weeks compared to open weeks, suggesting compliance to the fishing committee rule.

\footnotetext{
${ }^{11}$ Dependent children.

${ }^{12}$ The 2006 fishery census does not contain information on household size or income. We control for ethnicity because it is correlated with the use of fishing gear and religion. In the household survey sample ethnicity was omitted because all fishers belonged to the same ethnic group (Tofin). The ethnicities in the fishery census sample are reported in Table A.1 of the online appendix.
} 


\subsection{Compliance of traditional rule breakers to the fishing committee rule}

To examine how Voodoo fishers who break the traditional rule behave towards the fishing committee rule, we again look at the subsample of konou users. This subsample includes Voodoo adherents, who are thus breaking the traditional Voodoo-based rule, and fishers of other religions. We estimate an extended version of Eq.(3) that includes the indicator variable for Voodoo adherence and an interaction term between Voodoo adherence and the closing of the lake:

Konou $_{i t}=\gamma_{0}+\gamma_{1}$ Voodoo $_{i}+\gamma_{2}$ Closed $_{t}+\gamma_{3}$ Voodoo $_{i} \times$ Closed $_{t}+\tau_{t}+\lambda_{a}+X_{i}^{\prime} \Omega+\varepsilon_{i t a}$

If Voodoo fishers who break the traditional rule also comply less to the fishing committee rule (compared to non-Voodoo fishers) the estimate of $\gamma_{3}$ should be significantly positive. That is, among konou users we should find that Voodoo adherents use the konou more in closed weeks than other fishers.

\subsection{Estimation technique}

We rely on logistic regression to estimate Eq.(1)-(4). To address concerns of unobserved individual heterogeneity confounding our results, we use an individual fixed effects model to estimate Eq.(3) and Eq.(4). However, this model does not allow us to estimate the impact of the time-invariant variable Voodoo adherence in Eq.(1) and Eq.(2). We therefore estimate these two equations using a simple logit model. ${ }^{13}$ We report our estimation results in terms of odds ratios; marginal effects for the logit model and OLS can be found in Online appendix A.2 and A.3.2.

\footnotetext{
13 The individual effects in a fixed effects model absorb all time-invariant variables such as Voodoo adherence. The Hausman-Taylor model (Hausman and Taylor, 1981) offers the possibility of estimating the impact of timeinvariant regressors in a fixed effects model, but requires instruments that were not available in our data. In section 6.1. we use three alternative methods to address unobserved individual heterogeneity for Eq.(1) and Eq.(2).
} 


\section{Results}

Table 4 presents the results on compliance with the traditional Voodoo-based rule. Columns (1) and (2) show odds ratios for Eq.(1), without and with controls. The odds ratio for Voodoo fishers is smaller than one and statistically significant, indicating that on average Voodoo fishers are less likely to use the konou than other fishers (all else equal). Column (2) indicates that the odds of konou use in any given week are on average 78 percent lower for Voodoo fishers compared to other fishers. In terms of marginal effects, being a Voodoo adherent reduces the probability of using the konou by on average 21 percentage points (all else equal).

Columns (3) and (4) show odds ratios for Eq.(2), again without and with controls. The odds ratio for Voodoo fishers remains smaller than one and statistically significant at the 10 percent level when village dummy variables are included. We therefore rule out the competing explanation that unobserved village-level heterogeneity is driving the negative relation between konou use and Voodoo adherence. However, the effect of Voodoo adherence is substantially smaller when village dummies are included: the odds of using the konou are on average 33 percent lower for Voodoo fishers compared to other fishers. In terms of marginal effects, the probability of konou use is 6 percentage points lower for Voodoo fishers compared to other fishers (all else equal). ${ }^{14}$

The estimated coefficients for the control variables (reported in Online appendix A.2) show the expected signs. The odds of konou use are significantly higher for younger and

\footnotetext{
${ }^{14}$ The difference in effect size of Voodoo adherence between the survey (Eq.(1)) and census (Eq.(2)) samples could be due to the fact that Eq.(2) takes village-level confounding factors into account, but other explanations are possible. The census sample includes 28 additional villages, the dependent variables are measured differently (see Online appendix B) and the identity of the interviewer may matter: fishers may have been less inclined to report konou use to census interviewers working for the government, with whom they have had many conflicts in the past about fishing activities (Dangbégnon, 2000).
} 
wealthier fishermen, and increase the further we are in the shrimp fishing season. Education, household size and the dependency ratio do not significantly affect konou use in either sample. For the case of education, however, we should note that there is very little variation in education levels in both samples: 86 percent of fishers in the survey sample and 84 percent of fishers in the census sample have not had any education.

Table 5 presents the results for compliance with the fishing committee rule. Columns (1) and (2) show odds ratios for Eq.(3), with and without controls, and column (3) shows odds ratios for Eq.(4). The odds ratios for closed weeks are smaller than one and statistically significant in all columns. The last column indicates that the odds of konou use are on average 38 percent lower in closed weeks compared to open weeks (all else equal). ${ }^{15}$ This finding suggests that there is some, although limited, compliance to the fishing committee rule.

The odds ratio for the interaction term is close to one and not statistically significant. This result indicates that, among those who use the konou for fishing, Voodoo adherents are on average equally likely to use it in closed weeks as other fishers. In other words, Voodoo fishers who decide to break the traditional rule (by using the konou) display the same behaviour towards the fishing committee rule as non-Voodoo fishers.

We conduct a number of tests to verify the robustness of these findings. The results for Eq.(1), Eq.(3) and Eq.(4) are robust to the use of a larger unbalanced sample of 121 fishers, which includes fishers who were not interviewed in all weeks (this test is not relevant for Eq.(2), which relies on the census sample). The results for Eq.(1)-(4) are robust to the use of a linear OLS model. Finally, the results for Eq.(1) hold when we replace the time-varying dependent variable use of the konou in week $t$ by a time-invariant measure of overall compliance: total use of the konou across 14 weeks (dropping the time dimension from the analysis). Details on these

\footnotetext{
${ }^{15}$ Since the logit fixed effects model does not estimate intercepts, we do not report marginal effects for these regressions in Online appendix A.2.
} 
robustness checks and full results for all regressions in the paper can be found in Online appendix A.

What is the practical significance of our findings? From an environmental perspective one could argue that the optimal outcome is to end all fishing activities, including the use of the konou, so as to allow the lake ecosystem to recover. From this perspective, a reduction of the odds of konou use in the order of 33 percent (census sample) to 78 percent (survey sample) might be considered small. From an economic perspective, however, it does not seem optimal to reduce the use of the konou to zero, as this would imply a severe blow to local livelihoods. A less intensive use of the konou seems necessary, but to what extent the use of the konou needs to be limited depends on the nature of the ecosystem, the dynamics of the fishing stocks, the environmental impact of the konou and the weights placed on environmental and economic concerns.

To better grasp the economic costs of not using the konou, one could estimate how much revenue fishers forgo. An analysis of the productivity of the konou (explained in more detail in Online Appendix A.5) suggests that konou use may increase weekly shrimp fishing revenue by as much as 383 percent, although this estimate needs to be interpreted with caution due to data limitations. Nevertheless, our finding that a traditional, Voodoo-based institution still holds enough power to bring fishers to give up a substantial amount of extra shrimp fishing income seems non-negligible.

We similarly find some compliance regarding the fishing committee rule. That compliance is far from perfect should not surprise given the substantial benefits of free-riding on the compliance of others. Yet, the fact that there is some compliance may indicate that there is interest in establishing a system for collective restraint and better resource management. So, even though the effects we find are too small to speak of successful management institutions, they do indicate that these institutions contain some effective elements that are able to change 
fishing behaviour. These elements may be valuable in devising a better resource management strategy.

\section{Competing explanations}

\subsection{Unobserved individual heterogeneity}

In our analysis of compliance with the traditional rule we controlled for village-level unobservables, but not for individual-level unobservables. Our estimated relation between Voodoo adherence and the use of the konou may therefore result from unobserved individual heterogeneity. One specific concern relates to unobserved preferences for the traditional. Fishers with such a preference may reject both non-traditional religions (i.e. all religions other than Voodoo) and non-traditional fishing gear such as the konou.

As explained in section 4.4 (footnote 13), the individual fixed effects model or the Hausman-Taylor model, which control for unobserved individual-level heterogeneity, cannot be implemented in our case. We therefore turn to three alternative methods.

We start by addressing the specific concern that Voodoo adherents have a preference for the traditional. If this were the case, we would expect to find a negative relation between Voodoo adherence and other (relatively) recently introduced technologies as well. We test this by re-estimating Eq.(1) while replacing the dependent variable use of the konou in week $t$ by (time-invariant) dummy variables indicating ownership of a mobile phone, an electricity generator, a radio and a TV. ${ }^{16}$ The results, presented in Table 6, indicate that Voodoo fishers (or their households) are equally likely to own a mobile phone, electricity generator, radio or

\footnotetext{
${ }^{16}$ Except for the mobile phone, ownership of assets was recorded at the household level. However, 85 percent of sample fishers are head of the household and presumably have considerable decision making power regarding the purchasing of these items.
} 
TV compared to other fishers. ${ }^{17}$ This finding suggests that Voodoo adherents do not to reject recently introduced technologies more than others. It therefore seems unlikely that Voodoo fishers would reject productive fishing innovations such as the konou solely because of a preference for the traditional.

Aside from the specific concern of such unobserved preferences, there may be other unobserved characteristics related to Voodoo adherence and the use of the konou that confound our findings. Our second approach follows Oster (2013) and aims to assess the extent of the remaining omitted variable bias by looking at coefficient movements along with movements in R-squared values when control variables are included. This approach assumes that selection on unobservables is proportional to selection on observables.

Table 7 presents logit odds ratios for Eq.(1) when we consecutively control for the week variable, arrondissement dummies, the list of basic controls discussed in section 4.1 and the following additional control variables: the fisherman's relationship with the household head, his marital status, his number of wives, a dummy variable indicating whether he owns a mobile phone and three dummy variables indicating whether his household owns an electricity generator, a radio or a TV.

Table 7 shows that the odds ratio for Voodoo adherence fluctuates between 0.21 and 0.34 when controls are consecutively added. The odds ratio remains smaller than one and significant at the 10 percent level (although in the last two columns the p-value increases just above 0.10 ). The pseudo R-squared value is 0.06 when the time trend and arrondissement dummies are included and increases to 0.15 when all controls have been added, suggesting that the included controls are informative. We conclude that controlling for a variety of informative individual characteristics has a relatively limited effect on the estimated odds ratio for Voodoo

\footnotetext{
${ }^{17}$ Since we do not exploit the time dimension here, we can also use the larger unbalanced sample of fishers. The results are qualitatively the same, except that Voodoo adherents are significantly less likely to own a TV (see Table A.14 of the Online appendix).
} 
adherence, suggesting that there are no major unobservables that would entirely knock out the effect.

Our third approach follows a similar logic: we attempt to capture part of the unobserved individual effect with the use of a correlated random effects model (Wooldridge (2010), first proposed by Mundlak (1978)). To this end, we have identified a variable in our dataset that varies across time and individuals and does not give rise to reverse causation: "negative shocks to the weekly number of fishing days". Relying on this variable to implement the correlated random effects model, we find that the results for Voodoo adherence are qualitatively unchanged and quantitatively similar. Results and further details on the variable "negative shocks to the weekly number of fishing days" are provided in Online appendix A.4.1.

\subsection{Reporting bias regarding the use of the konou}

A potential caveat is that fishers may lie about konou use when the lake is closed. In this case we would overestimate compliance to the fishing committee rule. To verify whether there is reason for such concern, we examine the fluctuations of shrimp fishing revenue across open and closed weeks. ${ }^{18}$ As the konou is one of the most productive instruments used for shrimp fishing, any periodical variation in its use should be reflected in shrimp fishing revenue (when controlling for the use of other fishing gear). If fishers respect the fishing committee rule and abandon the konou in closed weeks, we should find that shrimp fishing revenue is lower in closed weeks compared to open weeks. Moreover, the abandonment of the konou in closed

\footnotetext{
${ }^{18} \mathrm{We}$ do not normalize fishing revenue by prices as prices are reported by local measures, which vary between villages, and greatly depend on the quality and size of shrimp. We therefore expect measurement error to be larger for recall data on prices than for recall data on nominal fishing revenue. Moreover, as most catches are sold within the same day, weekly fishing revenue should be strongly correlated with weekly catches. Finally, any price rise that follows from the closing of the lake will attenuate our estimates, reducing the risk of obtaining false positive results.
} 
weeks may increase fishing yield when the lake is re-opened, thus giving an additional boost to fishing revenue.

One possible objection is that self-reported data on fishing revenue might also suffer from reporting bias. We cannot completely rule out this possibility, but we do expect reporting bias in fishing revenue data to be much less severe. Weekly fishing revenue is reported by species, not by fishing instrument. As there are other high-yielding shrimp fishing instruments apart from the konou, such as shrimp pots, fishers can explain high shrimp fishing revenue in closed weeks by intensive use of these alternative, non-prohibited fishing instruments. We therefore believe that fishermen had little incentive to lie about shrimp fishing revenue in closed weeks.

Figure 3 depicts the fluctuation of weekly shrimp fishing revenue across open and closed weeks. The graph supports our hypothesis, showing that weekly shrimp fishing revenue generally drops in closed weeks compared to open weeks. The graph further shows a rise of shrimp fishing revenue in week 10 - a closed week - which indicates that fishers were not hesitant to report increases in revenue when the lake was closed. We also note a boost in revenues once the lake is opened again, which can certainly not be attributed to conscious misreporting by fishermen.

To examine the weekly fluctuations of shrimp fishing revenue more formally, we use a linear individual fixed effects model to estimate two equations. In the first equation we include indicator variables for each closed week, taking the open period as the baseline category. In the second equation we include indicator variables for each of the open weeks, taking the closed period as the baseline category. The two equations can be written as follows:

$$
\begin{aligned}
& F_{i t}=\omega_{0}+\omega_{1} \text { Closed }_{t}^{1}+\omega_{2} \text { Closed }_{t}^{2}+\tau_{t}+\varphi_{i}+\mathrm{K}^{\prime}{ }_{i t} \Theta+\varepsilon_{i t} \\
& F_{i t}=\omega_{0}^{\prime}+\omega_{3} \text { Open }_{t}^{1}+\omega_{4} \text { Open }_{t}^{2}+\omega_{5} \text { Open }_{t}^{3}+\omega_{6} \text { Open }_{t}^{4}+\tau_{t}+\varphi_{i}+{K^{\prime}}_{i t} \Theta+\varepsilon_{i t}
\end{aligned}
$$


$F_{i t}$ denotes shrimp fishing revenue for fisherman $i$ in week $t$; Closed $d_{t}^{w}\left(\operatorname{Open}_{t}^{w}\right)$ are indicator variables that take value 1 if the lake is closed (open) in week $t$ for the w-th consecutive week (and 0 otherwise); $\tau_{t}$ is a count variable as specified in Eq.(1); $\varphi_{i}$ are individual fixed effects (i.e. individual-level dummy variables); $\mathrm{K}^{\prime}{ }_{i t}$ is a vector of control variables; $\varepsilon_{i t}$ denotes the random error term clustered at the individual level. The control variables in $\mathrm{K}_{i t}^{\prime}$ reflect the fishery production function and capture the input of time, labour and capital. We include the logarithms of the number of fishing days and the number of persons fishing, and dummy variables indicating the use of the three main shrimp fishing instruments other than the konou.

Table 8 presents estimation results for Eq.(5) in columns (1) and (2). The coefficient estimate for the first week of closing is negative, large and statistically significant. The findings indicate that, all else equal, shrimp fishing revenue is on average 78 percent lower in the first week of closing compared to the average of open weeks. In contrast, the coefficient estimate for the second week of closing is small and not statistically significant. This finding may be explained by two mechanisms. First, in the second closed week fishermen may already start to benefit from less intensive konou use in the previous week through a higher yield for other fishing gear. Second, fishermen may resume their konou use already in the second closed week to reap the benefits of the restraint exercised by other konou users.

Columns (3) and (4) in Table 8 show estimation results for Eq.(6). The coefficient estimates for the first and second week of opening are positive, large and statistically significant. The results indicate that shrimp fishing revenue is on average 117 percent higher in the first open week and 67 percent higher in the second open week, compared to the average of closed weeks. The coefficient estimates for the third and fourth open weeks are positive but not statistically significant. These findings suggest that there is a strong increase in fishing revenue in the first two open weeks, which dies out in the third and fourth weeks of opening. One 
possible explanation is that intensive use of the konou in the first two open weeks reduces fishing yield again, driving down fishing revenue in the two weeks after. ${ }^{19}$

These findings are a strong indication of reductions in konou use when the lake is closed However, one may still object that the fluctuations in fishing revenue are caused by a natural cycle rather the fishing committee rule. We therefore perform a falsification test, comparing the fluctuations in shrimp revenue at Nokoué with those at another southern lake in Benin (Ahémé, see Figure 1), where similar natural conditions prevail but the fishing committee rule does not apply. Finding no significant differences between the two lakes would suggest that the fluctuations observed at Nokoué are caused by a natural cycle rather than the fishing committee rule. However, we find significantly larger fluctuations of shrimp revenue at Nokoué, suggesting that the observed fluctuations do not merely result from natural cyclicality (see Online appendix A.4.2 for details).

\footnotetext{
${ }^{19}$ The average estimated jump in fishing revenue in the first open week is larger than the average estimated drop in fishing revenue in the first closed week. A possible explanation is that the rise in fishing revenue in open weeks is also driven by an increase in overall fishing yield, and not merely the result of fishers resuming the use of the konou.
} 


\section{Conclusion}

The lake fisheries of southern Benin provide a textbook example of the tragedy of the commons. Overfishing has compromised the sustainability of the fishery stock, which has dramatically declined in the last decades (Clédjo, 2006; FAO, 2008).

Fishing activities at lake Nokoué - the largest lake in Benin - are regulated by two fishery management institutions, one embedded in the traditional Voodoo religion and one recent secular institution in the form of fishing committees. We have attempted to shed light on the effectiveness of each of these institutions. In addition, we have examined how Voodoo fishers who break with traditional Voodoo-based rules behave towards the recent fishing committee institution.

Regarding the traditional Voodoo-based institution, we have found a statistically significant negative relation between the use of the konou and Voodoo adherence, suggesting that Voodoo adherents respect the traditional fine mesh nets taboo more than others. This result remains, although it becomes weaker, when we take unobserved village-level heterogeneity into account. The relation is also robust to the use of different samples and model specifications.

In addition, we have addressed the competing explanation of an unobserved preference for the traditional, by showing that Voodoo adherents adopt other recently introduced technologies (e.g. the mobile phone and radio) to the same extent as other fishers. We have also shown that the inclusion of a variety of informative individual characteristics has little effect on the coefficient estimate for Voodoo adherence, thereby mitigating the concern that our results are driven by unobserved individual heterogeneity. Although we cannot completely rule out omitted variable bias, the results suggest that it is unlikely that such bias can entirely knock out the effect of Voodoo adherence. 
Regarding the fishing committee institution, we have found evidence for a statistically significant impact of the opening-closing rule on the use of the konou. However, quantitatively the impact is small. One possible explanation for the observed compliance is that collectively halting konou use for some weeks raises fishing yield in the following weeks, incentivizing konou users to respect the rule. The limited quantitative effect is likely explained by insufficient monitoring and corruption, which create incentives to free ride on the compliance of others.

One concern regarding these findings is that fishermen may lie about konou use in closed weeks. We have therefore studied the fluctuations of fishing revenue for shrimp - strongly correlated with konou use - across open and closed weeks. This analysis corroborates our findings regarding the fishing committee rule. Although we cannot completely rule out the possibility of fishermen also lying about fishing revenue, we have argued that it is unlikely that revenue data suffer from an equally severe reporting bias, reducing the concern that such bias is driving our findings on compliance with the fishing committee rule.

We have further found that Voodoo adherents who break the traditional rule comply to the fishing committee rule in the same way as other fishers. If it were the case that Voodoo rule breakers simply display free rider behaviour, we might expect these fishers to free ride on other fishing rules as well, and more so than other fishers. Our results instead suggest that Voodoo fishers who decide to abandon the (strict) traditional rule may still see the need to exercise some collective restraint and shift towards the fishing committee rule.

Our empirical findings confirm qualitative evidence on the continued role of the traditional Voodoo institution in regulating fishing activities at the southern lakes of Benin (Amoussou, 2004; Clédjo, 2006; République du Bénin, 2008). Our findings also resonate with those of several other studies (see introduction) and with recent research advocating an integrated resource management approach, where traditional institutions are combined with contemporary management institutions 
and technologies (Becker and Ghimire, 2003; Cinner and Aswani, 2007; Colding and Folke, 2001; Drew, 2005: Dudley et al., 2009).

At the same time, the above analysis is only a first step towards a quantitative assessment of the effectiveness and potential substitutability of these institutions. More research is needed to fully understand how these institutions and their interaction affect fishing behaviour, and what the policy implications are. Our first analysis suggests that both institutions affect fishing behaviour, but only in a limited way. In this case resource management needs to be strengthened. One integrated management strategy that is increasingly being implemented is the incorporation of sacred sites into official protected areas. Sacred forests in Benin are already being integrated into a national system of protected areas (GEF, 2010), and the southern lakes of Benin are similarly characterized by sacred sites. Nevertheless, the official protection of sacred sites also involves risks such as a loss of spiritual value (Dudley et al., 2009). Hence, careful research is needed to evaluate the potential success of this strategy. Future research could further examine whether other elements of the traditional Voodoo institution (such as the prohibition to fish on days of worship) can be valuably integrated into modern management institutions, or whether other religions can play a role in natural resource management. 


\section{Acknowledgements}

We are grateful for valuable comments from Gani Aldashev, Jean-Marie Baland, Erwin Bulte, Jean-Philippe Platteau, Nik Stoop, Jo Swinnen, Maarten Voors and David Zetland. We also thank seminar and conference participants at the University of Namur, the Wageningen University, the 2012 Institutions conference at Utrecht University, the 2013 EAAE PhD workshop at the University of Leuven and the 2013 DIAL conference at the Paris Dauphine University. Finally, we thank two anonymous referees of this journal for providing valuable comments and suggestions for improvement. This research was funded by the Centre for Institutions and Economic Performance (LICOS) under the Methusalem Grant and the Fund for Scientific Research - Flanders (FWOVlaanderen). Romain Houssa finally acknowledges financial support from the ACROPOLIS project. 


\section{References}

Afrobarometer. 2014. "Round 5 (2010-2012).” http://www.afrobarometer.org/.

Agrawal, Arun. 2001. "Common Property Institutions and Sustainable Governance of Resources.” World Development 29 (10): 1649-72.

Allan, J. David, Robin Abell, Z. E. B. Hogan, Carmen Revenga, Brad W. Taylor, Robin L. Welcomme, and Kirk Winemiller. 2005. “Overfishing of Inland Waters.” BioScience 55 (12): $1041-51$.

Amoussou, Ernest. 2004. "Systèmes Traditionnels de Gestion Durable Du Lac Ahémé Au Bénin." Développement Durable: Leçons et Perspectives, 263-70.

Atti-Mama, Cyriaque. 1998. "Co-Management in Continental Fishing in Benin: The Case of Lake Nokoué.” In The International Workshop on Fisheries Co-Management.

Baland, Jean-Marie, and Jean-Philippe Platteau. 1996. Halting Degradation of Natural Resources: Is There a Role for Rural Communities?. Food and Agriculture Organization.

Barbier, Jean-Claude, and Élisabeth Dorier-Apprill. 2002. "Cohabitations et Concurrences Religieuses Dans Le Golfe de Guinée. Le Sud-Bénin, Entre Vodun, Islam et Christianismes." Bulletin de L'association Des Géographes Français, 223-36.

Becker, C. Dustin, and Kabita Ghimire. 2003. "Synergy between Traditional Ecological Knowledge and Conservation Science Supports Forest Preservation in Ecuador.” Ecology and Society 8 (1): 1.

Berkes, Fikret. 1989. Common Property Resources: Ecology and Community Based Sustainable Development. Belhaven Press.

—. 2001. Managing Small-Scale Fisheries: Alternative Directions and Methods. IDRC.

- 2008. Sacred Ecology. 2nd ed. New York: Routledge. 
Berkes, Fikret, Johan Colding, and Carl Folke. 2000. "Rediscovery of Traditional Ecological Knowledge as Adaptive Management.”Ecological Applications 10 (5): 1251-62.

Bhagwat, Shonil A., and Claudia Rutte. 2006. "Sacred Groves: Potential for Biodiversity Management." Frontiers in Ecology and the Environment 4: 519-24.

Bourgoignie, Georges Edouard. 1972. Les Hommes de L'eau: Ethno-Écologie Du Dahomey Lacustre. Paris: Éditions universitaires.

Cinner, Joshua E., and Shankar Aswani. 2007. "Integrating Customary Management into Marine Conservation." $\quad$ Biological Conservation $140 \quad$ (3-4): $\quad$ 201-16. doi:10.1016/j.biocon.2007.08.008.

Clédjo, F.G.A.P. 2006. “La Gestion Locale de L’environnement Dans Les Cités Du Lac Nokoué Au Bénin Méridional.” Thèse de Doctorat (Thèse Unique), Ecole Doctoral Pluridisciplinaire FLASH DGAT UAC.

Colding, Johan, and Carl Folke. 2001. "Social Taboos: 'Invisible' Systems of Local Resource Management and Biological Conservation.” Ecological Applications 11: 584-600.

Cox, Michael, Gwen Arnold, and S. Villamayor Tomás. 2010. “A Review of Design Principles for Community-Based Natural Resource Management.” Ecology and Society 15 (4): 38.

Dangbégnon, Constant. 2000. "Governing Local Commons: What Can Be Learned from the Failures of Lake Aheme's Institutions in Benin." In Eighth Biennial Conference of the International Association for the Study of Common Property, Bloomington, Indiana, USA. http://dlc.dlib.indiana.edu/dlc/handle/10535/1339.

Deb, Debel, and K. C. Malhotra. 2001. "Conservation Ethos in Local Traditions: The West Bengal Heritage.” Society \& Natural Resources 14 (8): 711-24. doi:10.1080/08941920118542. 
Drew, Joshua A. 2005. "Use of Traditional Ecological Knowledge in Marine Conservation: Traditional Ecological Knowledge in Marine Conservation." Conservation Biology 19 (4): 1286-93. doi:10.1111/j.1523-1739.2005.00158.x.

Dudley, Nigel, Liza Higgins-Zogib, and Stephanie Mansourian. 2009. "The Links between Protected Areas, Faiths, and Sacred Natural Sites.” Conservation Biology 23 (3): 568-77. doi:10.1111/j.1523-1739.2009.01201.x.

Eneji, C. V. O., G. U. Ntamu, C. C. Unwanade, A. B. Godwin, J. E. Bassey, J. J. Willaims, and Joseph Ignatius. 2012. "Traditional African Religion in Natural Resources Conservation and Management in Cross River State, Nigeria." Environment and Natural Resources Research 2 (4): p45.

FAO. 2008. "Fishery and Aquaculture Country Profiles: Benin,” no. 700.

2012. The State of World Fisheries and Aquaculture 2012. Rome; London: Food and Agriculture Organization; Eurospan [distributor].

-2014. State of World Fisheries and Aquaculture 2014. Food \& Agriculture Organization.

GEF. 2010. “GEF's Programmatic Approach to Biodiversity Conservation in West and Central Africa." The Global Environment Facility.

Gnohossou, Pierre. 2006. “La Faune Benthique D’une Lagune Ouest Africaine (le Lac Nokoue Au Bénin), Diversite, Abondance, Variations Temporelles et Spatiales, Place Dans La Chaine Trophique."

Hausman, Jerry A., and William E. Taylor. 1981. "Panel Data and Unobservable Individual Effects.” Econometrica: Journal of the Econometric Society, 1377-98.

Hoestlandt, H. 1939. "Premières Recherches Sur Le Cycle Biologique de Penaeus Duoranrun Burkenroad En Afrique Occidentale.” Mémoire I.F.A.N., nº77. 
Jones, Julia P. G., Mijasoa M. Andriamarovololona, and Neal Hockley. 2008. “The Importance of Taboos and Social Norms to Conservation in Madagascar." Conservation Biology 22 (4): 976-86. doi:10.1111/j.1523-1739.2008.00970.x.

Juhé-Beaulaton, Dominique, and Bernard Roussel. 2002. "Les Sites Religieux Vodun: Des Patrimoines En Permanente Évolution.” In Patrimonialiser La Nature Tropicale: Dynamiques Locales, Enjeux Internationaux (Colloques et Séminaires), edited by MarieChristine Cormier Salem, Dominique Juhé-Beaulaton, Jean Boutrais, and Bernard Roussel, 415-38. Paris: Paris: IRD.

Kajembe, G. C., E. J. Luoga, M. S. Kijazi, and C. S. Mwaipopo. 2003. “The Role of Traditional Institutions in the Conservation of Forest Resources in East Usambara, Tanzania." The International Journal of Sustainable Development \& World Ecology 10 (2): 101-7.

Kokou, Kouami, Kossi Adjossou, and Adzo Dzifa Kokutse. 2008. "Considering Sacred and Riverside Forests in Criteria and Indicators of Forest Management in Low Wood Producing Countries: The Case of Togo." Ecological Indicators 8 (2): 158-69. doi:10.1016/j.ecolind.2006.11.008.

Mundlak, Yair. 1978. “On the Pooling of Time Series and Cross Section Data.” Econometrica 46 (1): 69-85. doi:10.2307/1913646.

Ntiamoa-Baidu, Yaa. 2008. "Indigenous Beliefs and Biodiversity Conservation: The Effectiveness of Sacred Groves, Taboos and Totems in Ghana for Habitat and Species Conservation.” http://ugspace.ug.edu.gh/handle/123456789/567.

Ormsby, Alison A., and Shonil A. Bhagwat. 2010. "Sacred Forests of India: A Strong Tradition of Community-Based Natural Resource Management.” Environmental Conservation 37 (03): 320-26. doi:10.1017/S0376892910000561. 
Oster, Emily. 2013. "Unobservable Selection and Coefficient Stability: Theory and Validation." National Bureau of Economic Research. http://www.nber.org/papers/w19054.

Ostrom, Elinor. 1990. Governing the Commons: The Evolution of Institutions for Collective Action. Cambridge univesrity press.

Pinkerton, Evelyn, ed. 2011. Co-Operative Management of Local Fisheries: New Directions for Improved Management and Community Development. UBC Press.

Pliya, Jean. 1980. La Pêche Dans Le Sud-Ouest Du Bénin. Etude de Géographie Appliquée Sur La Partie Continentale et Maritime. Paris: AGECOOP.

—. 1989. "Migrations Historiques et Peuplement Dans Les Régions Lagunaires Du Bénin Méridional."

République du Bénin. 1997. “Arrêté Interministériel N³12/MDR/MISAT/DCAB/CC/CP Portant Institution, Organisation, Attributions et Fonctionnement Des Comités et Conseils de Pêche En République Du Bénin.”

—. 2008. "Plan de Gestion de Plans d'Eau (PGPE): Lac Nokoué."

Sharma, Subrat, Hem C. Rikhari, and Lok Man S. Palni. 1999. "Conservation of Natural Resources Through Religion: A Case Study from Central Himalaya.” Society \& Natural Resources 12 (6): 599-612. doi:10.1080/089419299279461.

Stoop, Nik, Romain Houssa, and Marijke Verpoorten. 2013. "To Fish or Not to Fish? Resource Degradation and Income Diversification in Benin.” LICOS Discussion Paper.

Tall, Emmanuelle. 1995b. "De la démocratie et des cultes voduns au Bénin." Cahiers d'études africaines 35 (137): 195-208. doi:10.3406/cea.1995.2030.

—. 1995a. "Dynamique Des Cultes Voduns et Du Christianisme Céleste Au Sud-Bénin." Cahier Sciences Humaines 31 (4): 797-823. 
Veitayaki, J., A. Nakoro, T. Sigarua, and N. Bulai. 2011. "On Cultural Factors and Marine Managed Areas in Fiji." In Pacific Island Heritage Archaeology, Identity and Community, 37-49. Acton, A.C.T.: ANU E Press.

Wooldridge, Jeffrey M. 2010. Econometric Analysis of Cross Section and Panel Data. MIT press. 


\section{Tables and Figures}

Table 1: Characteristics of data samples used

\begin{tabular}{lcccc}
\hline \hline Characteristic & Fishery census & Household survey & $\begin{array}{c}\text { Household survey - } \\
\text { konou users }\end{array}$ & Perception survey \\
\hline Year & 2006 & 2009 & 2009 & 2013 \\
Arrondissements & 10 & 2 & 2 & 1 \\
Villages & 34 & 6 & 5 & 3 \\
Individuals & 5,852 & 103 & 47 & 137 \\
Weeks & $/$ & 14 & 14 & $/$ \\
Observations & 5,852 & 1,442 & 658 & 137 \\
\hline \hline
\end{tabular}

Source: Author's calculations. Notes: konou users are defined as fishers who report to have used the konou at least once during the survey period.

Table 2: Religious affiliation of fishers in two samples

\begin{tabular}{lcccc}
\hline \hline \multirow{2}{*}{ Religion } & \multicolumn{2}{c}{ Fishery census $(2006)$} & \multicolumn{2}{c}{ Household survey (2009) } \\
\cline { 2 - 5 } Catholicism & Share $(\%)$ & Obs & Share $(\%)$ & Obs \\
Protestantism & 22.5 & 1,317 & 27.2 & 28 \\
Islam & 12.9 & 757 & 11.7 & 12 \\
Voodoo & 3.3 & 192 & 0 & 0 \\
Christianisme Céleste & 23.5 & 1,375 & 27.2 & 28 \\
Other & 19.0 & 1,114 & 22.3 & 23 \\
None & 8.7 & 510 & 4.9 & 5 \\
Total & 10.0 & 587 & 6.8 & 7 \\
\hline \hline
\end{tabular}

Source: Author's calculations. 
Table 3: Share of konou users by religious adherence in two samples

\begin{tabular}{lcccccccc}
\hline \hline & \multicolumn{3}{c}{ Fishery census (2006) } & & & \multicolumn{3}{c}{ Household survey (2009) } \\
\cline { 2 - 3 } \cline { 7 - 9 } Religion & Konou users (\%) & Obs. & $\mathrm{N}$ & & Konou users (\%) & Obs. & $\mathrm{N}$ \\
\hline Voodoo & 19.6 & 269 & 1,375 & & 28.6 & 8 & 28 \\
Other & 34.2 & 1,530 & 4,477 & & 52.0 & 39 & 75 \\
Overall & 30.7 & 1,799 & 5,852 & & 45.6 & 47 & 103 \\
\hline \hline
\end{tabular}

Source: Author's calculations. Notes: Konou users are fishers who use the konou. In the household survey, we define a konou user as a fisher who reports to have used the konou at least once.

Table 4: Use of the konou and Voodoo adherence in two samples: Logit odds ratios

\begin{tabular}{|c|c|c|c|c|}
\hline \multirow{3}{*}{$\begin{array}{l}\text { Sample } \\
\text { Dependent variable } \\
\text { Variables }\end{array}$} & \multirow{2}{*}{\multicolumn{2}{|c|}{$\begin{array}{c}\text { Household survey } \\
\text { Use of the konou in week t }\end{array}$}} & \multirow{2}{*}{\multicolumn{2}{|c|}{$\begin{array}{c}\text { Fishery census } \\
\text { Use of the konou }\end{array}$}} \\
\hline & & & & \\
\hline & $(1)$ & $(2)$ & $(3)$ & (4) \\
\hline \multirow[t]{3}{*}{ Voodoo } & $0.362 * *$ & $0.219 * *$ & $0.468 * * *$ & $0.669^{*}$ \\
\hline & $(0.177)$ & $(0.133)$ & $(0.125)$ & $(0.162)$ \\
\hline & {$[0.038]$} & [0.012] & {$[0.004]$} & [0.097] \\
\hline Week & & v & & \\
\hline Arrondissement & & v & & \\
\hline Controls & & v & & $\checkmark$ \\
\hline Village & & & & 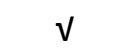 \\
\hline Constant & v & $v$ & $v$ & $v$ \\
\hline Number of clusters & 102 & 88 & 34 & 34 \\
\hline Observations & 1,190 & 1,039 & 5,852 & 5,160 \\
\hline
\end{tabular}


Table 5: Use of the konou and the fishing committee rule: Logit individual fixed effects odds ratios (2009 household survey - subsample of konou users)

\begin{tabular}{|c|c|c|c|}
\hline \multicolumn{4}{|c|}{ Dependent variable: Use of the konou in week $\mathrm{t}$} \\
\hline Variables & $(1)$ & (2) & (3) \\
\hline \multirow[t]{3}{*}{ Closed } & $0.583 * * *$ & $0.620 * * *$ & $0.621 * * *$ \\
\hline & $(0.084)$ & $(0.091)$ & $(0.100)$ \\
\hline & {$[0.000]$} & {$[0.001]$} & {$[0.003]$} \\
\hline \multirow[t]{3}{*}{ Voodoo*Closed } & & & 0.994 \\
\hline & & & $(0.373)$ \\
\hline & & & [0.988] \\
\hline Week & & $\sqrt{ }$ & $\sqrt{ }$ \\
\hline Number of clusters & 43 & 43 & 43 \\
\hline Observations & 550 & 550 & 550 \\
\hline
\end{tabular}

Notes: Odds ratios are reported with individually clustered robust standard errors in parentheses and p-values in square brackets. ***, ** and $*$ denote significance at the 1,5 and $10 \%$ levels respectively. Columns (1) and (2) show estimation results for Eq.(3). Column (3) shows estimation results for Eq.(4). The regression sample is limited to the subsample of konou users, i.e. fishers who report to have used the konou at least once during the survey period. The conditional logit fixed effects model does not estimate intercepts or coefficients for time-invariant regressors such as Voodoo adherence. Week refers to a count variable that indicates the week of observation. 
Table 6: Ownership of recent technologies and Voodoo adherence: Logit odds ratios (2009 household survey)

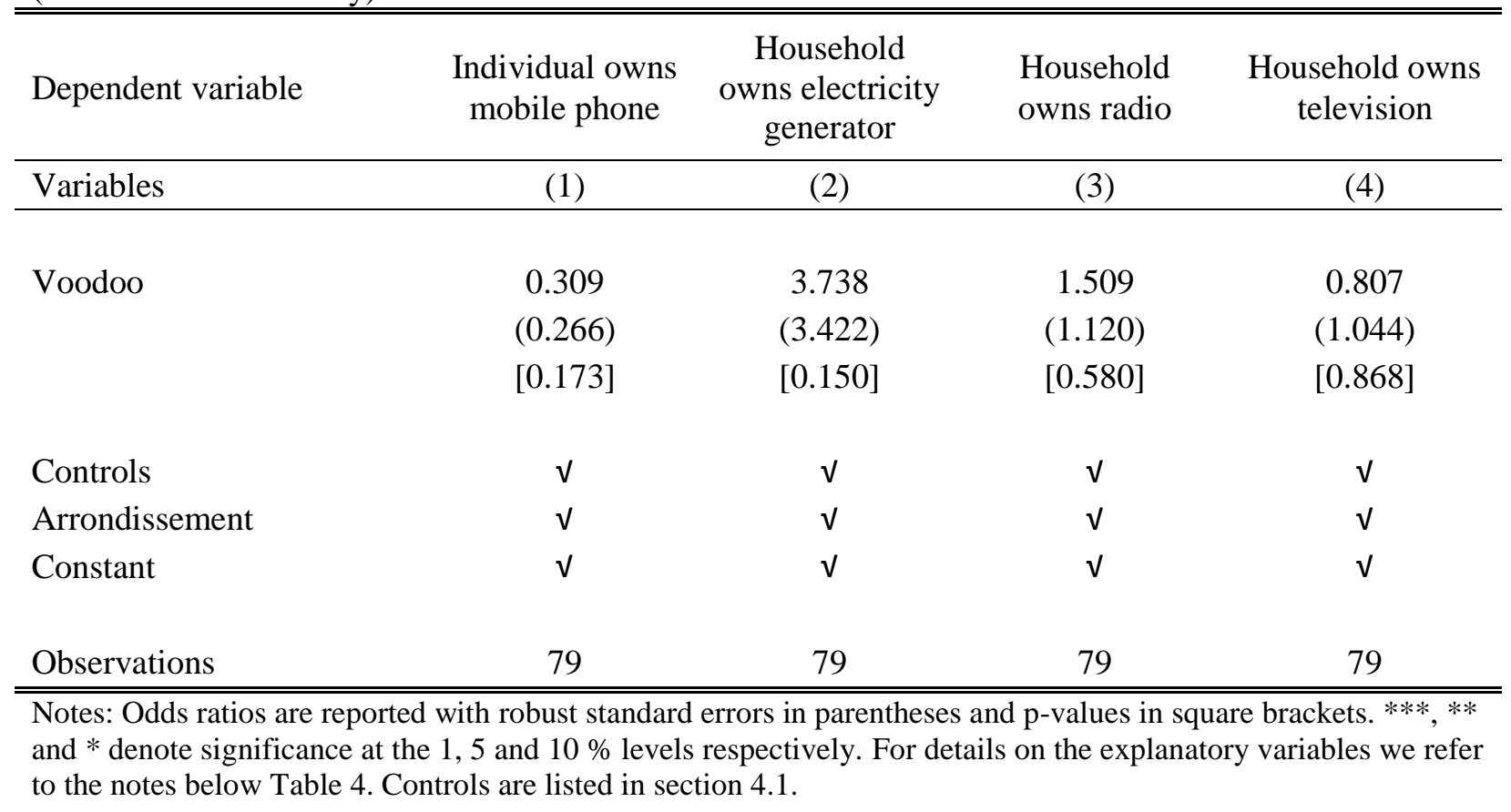


Table 7: Use of the konou and Voodoo adherence: inclusion of additional control variables - Logit odds ratios (2009 household survey)

\begin{tabular}{|c|c|c|c|c|c|c|c|c|c|c|c|}
\hline Dependent variable & Use of th & konou in & reek t & & & & & & & & \\
\hline Variables & (1) & (2) & (3) & (4) & (5) & (6) & (7) & (8) & (9) & (10) & (11) \\
\hline \multirow[t]{3}{*}{ Voodoo } & $0.362 * *$ & $0.344 * *$ & $0.210 * *$ & $0.219 * *$ & $0.214 * *$ & $0.214 * *$ & $0.233 * *$ & $0.273 *$ & $0.307 *$ & 0.331 & 0.331 \\
\hline & $(0.177)$ & $(0.173)$ & $(0.129)$ & $(0.133)$ & $(0.132)$ & $(0.133)$ & $(0.152)$ & $(0.189)$ & $(0.218)$ & $(0.231)$ & $(0.230)$ \\
\hline & {$[0.038]$} & {$[0.033]$} & {$[0.011]$} & {$[0.012]$} & {$[0.013]$} & {$[0.013]$} & {$[0.025]$} & {$[0.060]$} & [0.096] & {$[0.113]$} & {$[0.112]$} \\
\hline Week & & $\checkmark$ & $\checkmark$ & $\checkmark$ & $\checkmark$ & $\checkmark$ & $\checkmark$ & $\checkmark$ & $\checkmark$ & $\checkmark$ & $\checkmark$ \\
\hline Arrondissement & & & $\checkmark$ & $\checkmark$ & $\checkmark$ & $\checkmark$ & $\checkmark$ & $\checkmark$ & $\checkmark$ & $\checkmark$ & $\checkmark$ \\
\hline Basic controls & & & & $\checkmark$ & $\checkmark$ & $\checkmark$ & $\checkmark$ & $\checkmark$ & $\checkmark$ & $\checkmark$ & $\checkmark$ \\
\hline $\begin{array}{l}\text { Relationship household } \\
\text { head }\end{array}$ & & & & & $\checkmark$ & $\checkmark$ & $\checkmark$ & $\checkmark$ & $\checkmark$ & $\checkmark$ & $\checkmark$ \\
\hline Marital status & & & & & & $\checkmark$ & $\checkmark$ & $\checkmark$ & $\checkmark$ & $\checkmark$ & $\checkmark$ \\
\hline Number of wives & & & & & & & $\checkmark$ & $\checkmark$ & $\checkmark$ & $\checkmark$ & $\checkmark$ \\
\hline Mobile phone & & & & & & & & $\checkmark$ & $\checkmark$ & $\checkmark$ & $\checkmark$ \\
\hline Electricity generator & & & & & & & & & $\checkmark$ & $\checkmark$ & $\checkmark$ \\
\hline Radio & & & & & & & & & & $\checkmark$ & $\checkmark$ \\
\hline $\mathrm{TV}$ & & & & & & & & & & & $\checkmark$ \\
\hline Constant & $\checkmark$ & $\checkmark$ & $\checkmark$ & $\checkmark$ & $\checkmark$ & $\checkmark$ & $\checkmark$ & $\checkmark$ & $\checkmark$ & $\checkmark$ & $\checkmark$ \\
\hline Observations & 1,190 & 1,190 & 1,190 & 1,039 & 1,039 & 1,039 & 1,039 & 927 & 927 & 927 & 927 \\
\hline Number of clusters & 102 & 102 & 102 & 88 & 88 & 88 & 88 & 79 & 79 & 79 & 79 \\
\hline pseudo R-squared & 0.026 & 0.041 & 0.058 & 0.113 & 0.124 & 0.125 & 0.127 & 0.146 & 0.150 & 0.154 & 0.154 \\
\hline
\end{tabular}

Notes: Odds ratios are reported with individually clustered robust standard errors in parentheses and p-values in brackets. ***,** and * denote significance at the 1,5 and $10 \%$ levels respectively. Basic controls refer to the list of control variables discussed in section 4.1. For more details on the explanatory variables we refer to the notes below Table 4 . 
Table 8: Shrimp fishing revenue across weeks: Linear individual fixed effects estimates (2009 household survey)

\begin{tabular}{lcc}
\hline \hline \multicolumn{2}{l}{ Dependent variable: $(\log )$ Fishing revenue for shrimp in week t } \\
\hline Variable & $(1)$ & $(2)$ \\
Closed first week & $-1.186^{* * *}$ & $-0.783^{* * * *}$ \\
& $(0.277)$ & $(0.253)$ \\
Closed second week & {$[0.000]$} & {$[0.003]$} \\
& $-0.505^{* *}$ & -0.094 \\
& $(0.233)$ & $(0.221)$ \\
& {$[0.033]$} & {$[0.671]$}
\end{tabular}

Open first week

$\begin{array}{cc}1.513 * * * & 1.169 * * * \\ (0.305) & (0.280) \\ {[0.000]} & {[0.000]} \\ 1.179 * * * & 0.670 * * \\ (0.346) & (0.311) \\ {[0.001]} & {[0.034]} \\ 0.990 * * * & 0.375 \\ (0.347) & (0.319) \\ {[0.005]} & {[0.242]} \\ 0.632 * * & 0.228 \\ (0.245) & (0.243) \\ {[0.011]} & {[0.350]}\end{array}$

Week

Controls

Constant

Observations

1,438

Number of clusters

103

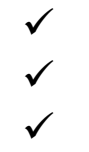

R-squared

0.02

1,184

1,438

1,184

102

103

102

Notes: Coefficients are reported with individually clustered robust standard errors in parentheses and p-values in square brackets. $* * *, * *$ and $*$ denote significance at the 1,5 and $10 \%$ levels respectively. Fishing revenue is expressed in CFA; one euro equaled about $656 \mathrm{CFA}$ in 2009. For details on the explanatory variables we refer to the notes below Table 4 and section 6.2. 
Figure 1: Location of the southern lakes and the 2009 household survey area in Benin
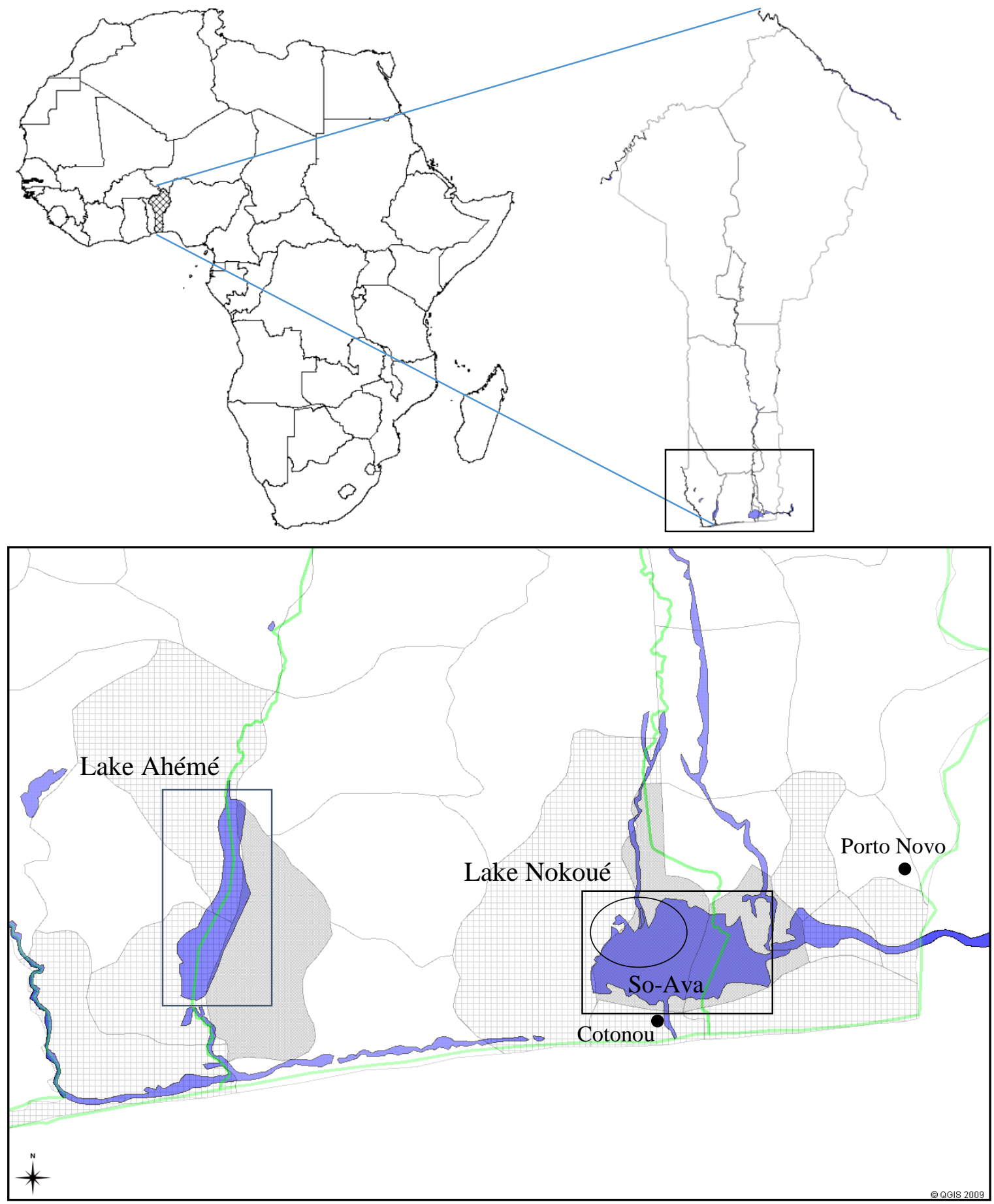
Figure 2: Share of fishers using the konou in each week, across open and closed weeks

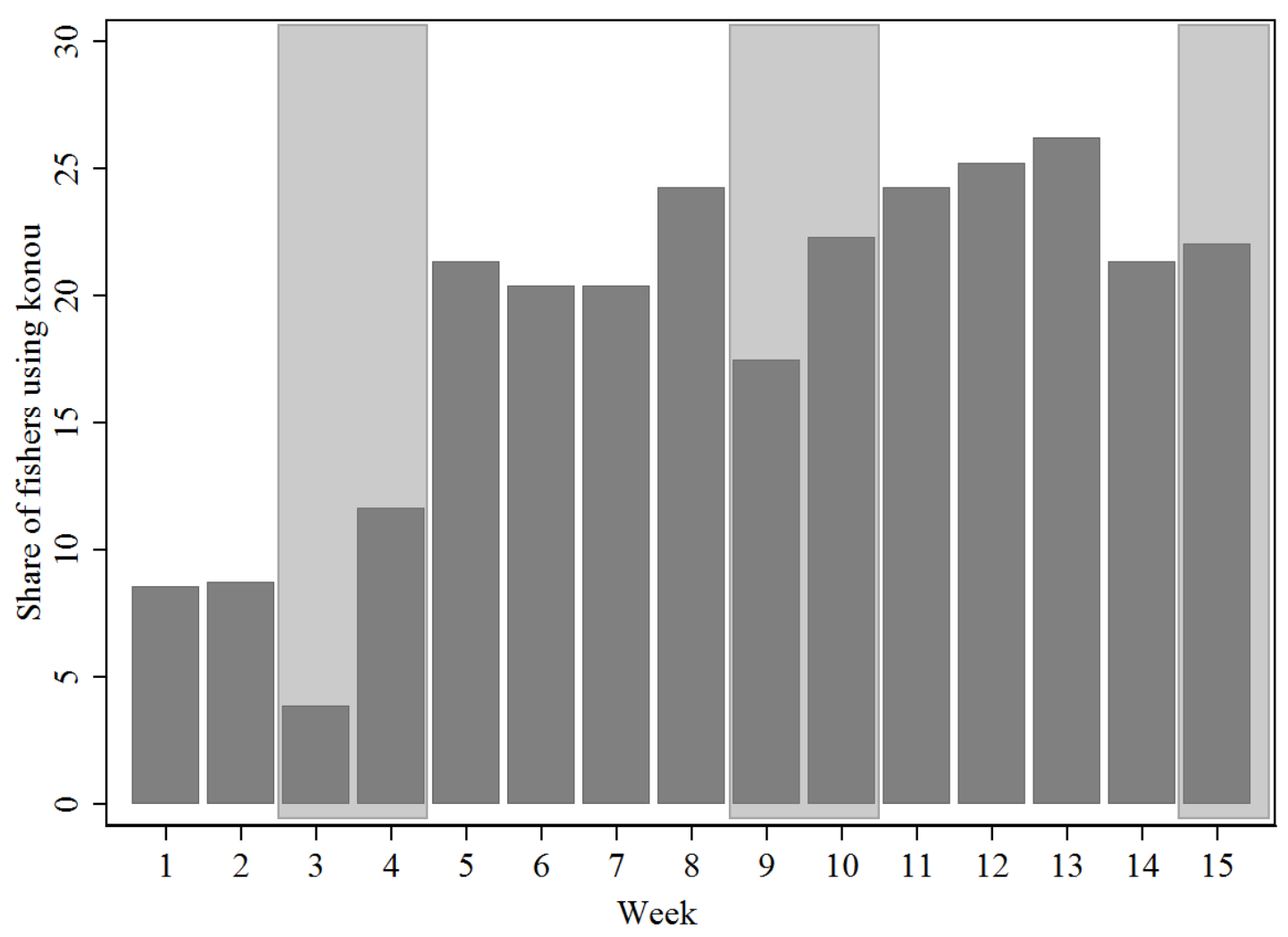

Source: Author's calculations.

Notes: Light-grey areas indicate closed weeks. Konou users are fishers who report to have used the konou at least once during the survey period. 
Figure 3: Average weekly shrimp fishing revenue across open and closed weeks

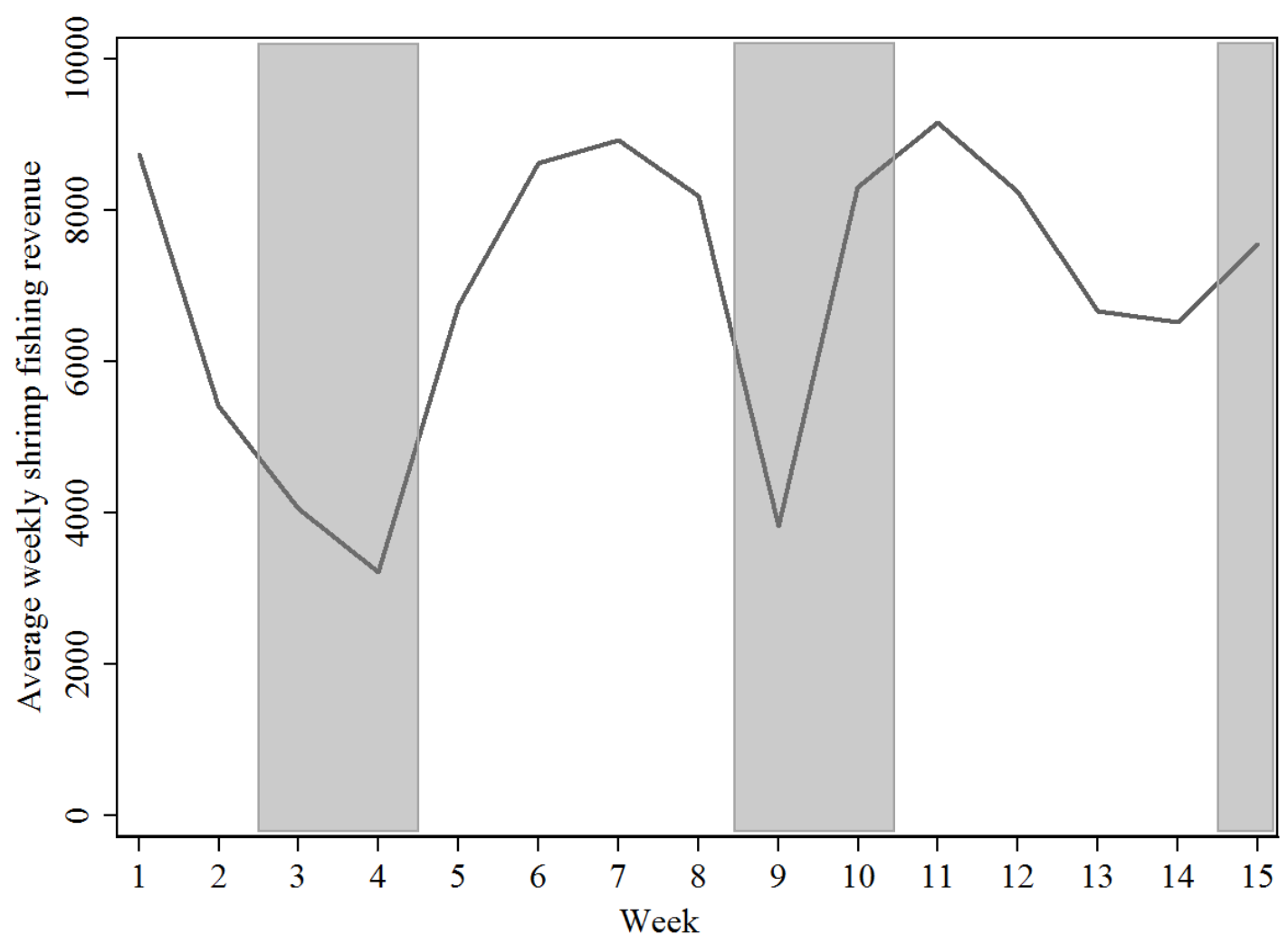

Source: Author's calculations.

Notes: Light-grey areas indicate closed weeks. Fishing revenue is expressed in CFA; one euro equalled about 656 CFA in 2009. 